\title{
The Impact of Information and Communication Technologies on the Emotional Education of Children with Autism Spectrum Disorder. Views of Specialist Educators and Psychologists
}

\author{
Eftychia Papageorgiou \\ Aristotle University of Thessaloniki, Thessaloniki, Greece \\ Email: epapageorgiou@hotmail.com
}

How to cite this paper: Papageorgiou, E. (2020) The Impact of Information and Communication Technologies on the Emotional Education of Children with Autism Spectrum Disorder. Views of Specialist Educators and Psychologists. Open Access Library Journal, 7: e6248. https://doi.org/10.4236/oalib.1106248

Received: March 20, 2020

Accepted: April 27, 2020

Published: April 30, 2020

Copyright $\odot 2020$ by author(s) and Open Access Library Inc.

This work is licensed under the Creative Commons Attribution International License (CC BY 4.0).

http://creativecommons.org/licenses/by/4.0/

\begin{abstract}
The present paper is entitled "The Impact of Information and Communication Technologies on the Emotional Education of Children with Autism Spectrum Disorder. Views of specialist educators and psychologists". The purpose of this work is to investigate how information and communication technologies influence the education of children with ASD. In the first part, a bibliographical review of the reported subject was taken place and the most important elements were presented. Then the practical part was followed, which included twenty interviews of specialist teachers (ten psychologists and ten specialist educators). Once the interviews were coded, the results were recorded and the conclusions drawn. Finally, the annexes and bibliography were presented.
\end{abstract}

\section{Subject Areas}

Education, Psychology

\section{Keywords}

Autism Spectrum Disorder, Emotional Education, Information and Communication Technologies, Influence

\section{Introduction}

Autism is a disorder that is most often diagnosed in early childhood and falls into the Autism Spectrum Disorder. The difficulties children with autism face are numerous and cover a wide range, from which the name of the disorder originated, with the main ones being in the field of communication and social inte- 
raction and stereotyped, repetitive behaviors [1].

Concerning the epidemiological features of autism, researchers report that boys are diagnosed with the disorder more frequently than girls, with the ratio being 4.3 boys to 1 girl [2]. Worldwide, about 62 in every 10,000 people are diagnosed with autism each year [3]. Autism also has a high comorbidity, which means that a child with autism is more likely to develop some other forms of disorder. Remarkably, about $70 \%$ of people diagnosed with autism also have intellectual disabilities, which can range from mild to severe [4].

As for the symptoms of the disorder, they are numerous and affect different areas of the child's development. For convenience, autism symptomatology is most commonly categorized into the following categories: language and communication, social interaction, mobility, and other symptoms that do not clearly fall into one category [5].

One area in which the difficulties of a child with autism become more intense is the emotional one. The child has difficulty both expressing himself emotionally and understanding the feelings of others around him. A variety of approaches can be used to address the symptoms of autism and the obstacles it creates in a child's life. One approach that is increasingly encountered in the literature is the utilization of Information and Communication Technologies (ICT). The development of digital technology now offers countless modern and sophisticated tools that can be used, with particularly impressive results, to support people with disabilities [6].

The benefits of ICT in the education and support of children with autism are manifold, as they offer clear and predefined boundaries, stimulus limitation, high levels of control, unlimited personalization options for pupils' needs, verbal and non-communicative possibilities, independence and possibility of attracting and retaining students' attention to the activity [7].

Exploiting ICT can offer many benefits to students with autism, helping them to express, recognize and understand other people's feelings and different expressions, as well as better learn their emotions, cultivate empathy, develop their social skills, to learn to adapt their behavior according to the circumstances and, in general, to achieve a better quality of life [8]. The role of ICTs in the emotional education of children with autism and the views and knowledge of specialist educators and psychologists on these, are issues to be addressed in this project.

It is particularly important to mention here the main purpose of the research carried out, as it is directly linked to each methodological stage that will be described below. The purpose of the present study was therefore to investigate the views of specialist educators and psychologists on the impact of Information and Communication Technologies (ICT) on the emotional education of children diagnosed with Autism Spectrum Disorder.

The main purpose of the research thus facilitated the definition of its individual objectives. Initially, the aim was to reflect the general attitude of the participants towards the use of new technologies in special education, especially in children with autism. As a consequence, the aim was to understand the partici- 
pants' knowledge of new technologies, both in terms of the materials and tools they offer and the results they bring and the facilities they provide in the area of special education. Finally, the aim was to outline the situation in Greece regarding the extent to which new technologies are being used in the classroom, to identify the difficulties that special educators face in implementing them, the types of new technologies being utilized, the ways in which their implementation can improve or make educational work more difficult, and if the training they receive is sufficient to successfully and effectively use new technologies to enhance and support the teaching of children.

The organization of the research, the selection of the appropriate methodology and the design of the research tool utilized, were based on a series of research questions, which in turn were raised following the definition of the purpose and objectives of the research and the study of the existing literature on the subject. The research questions of the research are listed below:

$>$ Do special educators and psychologists know about existing New Technologies in the field of emotional education for children with ASD?

$>$ What are the views of specialist educators and psychologists on the role of New Technologies in the emotional education of children with ASD?

Are there any inhibiting factors in the use of New Technologies in the field of emotional education of children with ASD?

How do specialist educators and psychologists evaluate their skills in the software domain used for emotional education of children with ASD?

Are there any differences between the areas of emotional education in their teaching through the New Technologies?

\section{Theoretical Framework}

\subsection{Autism}

Autism is a developmental disorder of man, a disorder of one's psychological development. This disorder includes:

$>$ qualitative difficulties in social understanding, transaction and emotional reciprocity,

$>$ difficulties in communication and language,

$>$ a limited, stereotyped, repetitive repertoire of activities and interests, while behavior is characterized by unique interests and hobbies,

uneven development of cognitive functions,

often inconsistent sensory processing.

These difficulties and limitations, which vary from person to person, are a pervasive feature of its functionality. In all forms of autism even in the mild, there are some disorders and difficulties in the functioning of the individual that require intervention. Autism often coexists with mental retardation, other disabilities or even with medical syndromes and conditions. The situation is perceived as the child grows up. The diagnosis can be made reliably between 2 and 3 years. Early and valid diagnoses are being promoted today. In all cases, by ap- 
plying appropriate psychological-educational-therapeutic approaches, provided they are applied early, systematically and consistently, there are opportunities to improve the situation, in some cases in a very important scale.

The disorder has a unique complexity that needs specialized interventions, from properly trained executives on a personalized basis and with other children in day care centers, schools. Interventions should follow the developmental path and be continuous from phase to phase throughout the life of the individual as needed.

Leo Kanner and Hans Asperger were both born in Austria, studied in Vienna but never met. Asperger was ten years younger, while Kanner left for America in 1924 and took over the John Hopkins Clinic in Baltimore.

In 1943 Kanner first described autism. At the time, he believed that people with autism had normal intelligence, but as it was later revealed, a significant proportion of children had "intellectual disabilities" and severe learning difficulties. The term mental retardation is used for the more general cognitive-perceptual developmental disorders. Autism also coexists with language disorders and often speech. At first he talked about "parent refrigerators", which he later canceled himself, and of course we know today that this is not the case.

Unaware of Kanner's work, Asperger described a class of children in 1944, which he called "autistic psychopathy". Today, diagnostic systems and classifications when referring to Asperger's Syndrome describe people with autistic disorders but with high functionality and with a marginal to normal intelligence index and language structure skills. Like many people with autism may have special abilities in some areas (artistic, numeracy, general memorization, computers, etc.).

Many related disorders have been grouped under the term "Diffuse Developmental Disorders" (P.D.D. in English), a general category of disorders characterized by various and pervasive disabilities in various areas of development [1]. A standard source is the Diagnostic \& Statistical Manual (DSM), a diagnostic book in its 4th edition. The DSM-IV lists criteria that meet for a specialized diagnosis under the category of "Diffuse Developmental Disorders". The diagnosis is made when a certain number of features reported in the DSM-IV and ICD-10 occur. Diagnostic evaluations are based on the presence of specific behaviors that are based on observation and through family observations and must be set by a specialized and highly trained team. When specialists or parents end up with different types of autism, they often distinguish autism from one of the other types of "diffuse developmental disorders".

Individuals diagnosed under the term "diffuse developmental disorders" in the DSM-IV show similarities in communication and socialization, but differ in diversity data. We highlight some key points that help us distinguish the differences between specialized diagnoses:

> Autistic Disorder. Severe malfunctions in social interaction, communication and imaginative play that occurred before the age of 3 years. Stereotypical expression of behaviors, interests and actions. 
Asperger's Disorder. characterized by disabilities in social interaction and the appearance of limited interests and actions, with no significant clinical delay in language while intelligence test results showing moderate or superior physiological intelligence.

> Diffuse Developmental Disorder, or otherwise identified (PDD-NOS) (often referred to as atypical autism): this diagnosis can be made when the child does not meet the criteria for specialized diagnosis, but there is variety and pervasive disability in specific behaviors.

Rett disorder. a progressive disorder which has so far only appeared in girls. A period of normal development is reported, followed by loss of previous abilities, loss of intentional use of hands that are replaced by repeated hand movements beginning at the age of 1 - 4 years.

Childhood Disorganization Disorder, characterized by normal development up to at least the first 2 years, a marked loss of prior acquired abilities.

Autism is a spectral disorder. In other words, the symptoms and features of autism can occur in a wide variety of combinations, from mild to varied. Although autism is elucidated by a particular set of behaviors, children and adults may exhibit any combination of behaviors at any degree of variety. Two children with the same diagnosis may react very differently and their actions may vary.

Thus, there is no "standard" or "typical" autistic person. Parents may hear different terms used to describe children with autism spectrum such as: autistic behavior, autism tendency, autism spectrum, high-functioning or low-functioning autism, more capable - less capable. Most important to understand is, whatever the diagnosis, that children can learn and function productively and show progress with appropriate education and treatment. The Autistic Society of America provides guidance to help the needs of all people with this spectrum disorder.

Diagnostic categories have changed over the years as research has progressed and new versions of the DSM have come out. For this reason and for short, we will use the term "autism" to refer to the above disorders, even if their diagnosis is different.

\subsection{Weaknesses}

Autism Spectrum Disorders are characterized by a heterogeneity. However, the characteristics of people with autism appear to be constant, regardless of intensity and frequency. At first these people have some weaknesses. One of the most common elements is deficits in verbal communication and especially in the field of semantics and pragmatics. Children with autism often fail to grasp the context and meaning of words, especially when they are used metaphorically. At the same time, they cannot adjust their speech according to the context and the people they are addressing to. In this way, as Shane \& Albert (2008) [9] report, children with autism have difficulty processing the spoken language. Of course, there are many cases of children who do not speak. These individuals may have 
no functional reason or be sound [10] [11].

Deficits, however, are not limited to verbal communication but extend to non-verbal communication. Non-verbal communication involves eye contact, body language-gestures, and facial expressions. People with autism avoid eye contact with another person. At the same time, facial expressions and gestures are absent, which makes this form of communication difficult. In the past, they tried to teach people with autism sign language (deaf community) in an attempt to find a way to communicate.

Social relationships are another area of difficulty for autistic people. They usually avoid social interaction and are isolated. At times, they may be trying for social contact, especially High Functioning people, but they cause annoyance to their interlocutors. Autistic people do not understand the impact of their behavior on others and can often act annoyingly. At the same time, their self-centered behavior, their echolalia, and their inability to follow social rules are reasons that discourage other people from interacting with them.

One factor that makes social interaction even more difficult is the inability to recognize emotions. Individuals in the spectrum have difficulty processing the feelings of others and fail to take them into account in their social interaction. They usually do not turn their attention to the persons who interact with them and it is often observed that they do not recognize familiar persons. Key features of this group are repetitive behaviors, or stereotypes, and attachment to points of interest.

At the same time, they also have deficits in written reason. Writing is a complex activity that requires a combination of a variety of processes, both cognitive and linguistic, where pragmatism, that is the social context upon which the text is written, plays an important role. Children with autism cannot take into account the social context when writing a text. In addition, they often fail to put their thoughts in order to compose a text [12].

\subsection{The Concept of Information and Communication Technologies}

It is even realized in our daily lives that technology, with its constant developments, improvements and, consequently, the facilities it offers to man, has become an integral part of our lives. Indeed, technology, with its diverse tools and the various forms it can take, has penetrated almost every aspect of human activity, from the professional, social, creative and entertainment sectors to the field of education.

These technologies are collectively known as Information and Communication Technologies (ICTs), a term that is becoming more and more common, especially in the field of education and in particular in special education. The term Information and Communication Technologies (ICT) came from English and the term "Information and Communication Technologies (ICT)". This term "umbrella" essentially refers to applications and electronic devices, such as computers, smartphones, satellite systems, etc., which facilitate and enable direct 
communication, information and updating [13] [14].

Karakiza [15] defines Information and Communication Technologies as the variety of digital media available to a user that enables them to search, locate and gain access to information they want, instantly and quickly. In order to identify the desired information, ICTs offer a variety of different tools and channels to the user, which allow him not only to search for information but also to process and modify it according to his needs and present it in a way who wishes to collect, store and analyze it and then pass it on to other users.

\subsection{Information and Communication Technologies in Education}

The rise of ICT is clearly inextricably linked to the expansion of the Internet to every corner of the world and the new technologies that have emerged with it, especially in recent years. Now, access to the Internet at anytime and anywhere is easier than ever, with new applications and tools being developed as a result of the ever-growing need for users to have access to valid and quality information, which offers new and more effective solutions for searching, locating and controlling the most intangible amount of information available on the vast web [15].

It is logical that these technological developments and the new world that is being opened up by the spread of ICTs, has now entered the educational field as well. The role of ICTs in the field of education appears to be particularly important and supportive as they can facilitate and enhance the educational process and make the learning process more interactive and therefore fun for students. ICTs offer a wide range of different tools and applications that facilitate the work of the teacher while at the same time assimilating and practicing students' knowledge. Some of these tools are databases, e-books, encyclopedias and scientific journals. Their utilization provides unobstructed and immediate access to information through a variety of databases, electronic journals, learning management systems, and a host of educational tools, software and applications that complement and enhance the curriculum [16].

The issue of introducing ICT into the field of education has been of concern to researchers and educators, as evidenced by a search in existing international literature. Indeed, one issue that comes up again and again concerns the use or not of ICTs by general education teachers, their familiarity with them and the ways in which they are applied in the classroom. In his research, Becker [17] found that for the most part, teachers were not familiar with ICT, its uses, the tools they offer, and therefore the ways in which they can be used in the classroom to enhance the learning process.

Russell et al.'s research [18], conducted by teachers and students of pedagogical schools who participated in preparatory curricula, has brought similar findings to the surface. According to the findings of this study, it appears that while teachers have a general view of ICT, they are interested in learning about their proper and effective use and are aware of some of the ways they could potentially 
be used in the classroom, the majority of them used ICT tools to improve communication during the lesson and facilitate presentation of the material rather than enhancing students' interaction with the object of the training and the assistance of the educational process. These findings lead to the conclusion that despite the fact that a number of teachers are familiar with the use of ICTs, they are substantially poorly trained and lack sufficient information about their multiple uses and their significant contribution to the educational process.

\subsection{Information and Communication Technologies in Special Education}

In the area of special education, ICT seems to be a powerful tool to assist both the educational process and the students with disabilities and learning difficulties themselves. The issue of providing appropriate education to students with disabilities has been one of the issues that has come up again and again in educational circles, especially in recent years where concepts such as inclusion and co-education have come to the fore more and more often. This burning issue of educating children with learning difficulties and disabilities focuses on ways in which these students can gain equal rights and opportunities in education, unhindered access to all infrastructure, services, goods and privileges enjoyed by students without disabilities, the elimination of the stigma that unfortunately still accompanies the word disability and learning difficulty, as well as the ways in which responsible people, including teachers, can help to facilitate the integration of students in school and assist the learning process. In this context, ICTs are again playing an important role, providing the necessary tools to facilitate the education of students with disabilities and their integration into the school environment and the wider society [19].

The school space is a place where all children should feel welcomed, regardless

of gender, social, economic, educational and cultural background. The right to education, after all, should be accessible to all students. However, access to education for students with disabilities is not always easy. There are many schools that do not have the appropriate building and logistical infrastructure to accommodate people with disabilities in their area and to provide them with unhindered access to learning and knowledge, with methods, materials and teachers that will meet their particular needs. It is essential and vital that these pupils' needs and schools are thoroughly considered and adapted so that they are able to provide the education they deserve and are entitled to. Clearly, the most important role in this issue is played by the competent educational institutions and, by extension, the principals and teachers in the schools where students with disabilities are attending, who must ensure that no pupils are excluded from the learning process [20].

In view of the above, it is concluded that students with disabilities should have equal opportunities in learning and at the same time, special tools and materials at their disposal that will help them to develop and cultivate their potential. ICTs 
come to provide appropriate support and software, which will assist the work of specialist education teachers, while facilitating the learning process for the students themselves. ICT, with its rich interactive learning materials and software available for use in the classroom, facilitates the learning process as it allows the virtual representation of complex concepts, thereby contributing to a better understanding of them. In addition, as ICTs utilize interactive environments, with images, audio, movements and videos, it allows students with disabilities to use all their senses, enhancing the sense of inclusion. Nevertheless, teachers' lack of knowledge of the role, utility and ways of utilizing ICT in the classroom, impedes their implementation and deprives students of a multifaceted tool to enhance learning [21].

Fernandez-Batanero and Colmenero-Ruiz [22], in their research conducted in inclusion teachers, brought to the fore some interesting findings. Research has shown that in the majority of teachers, teachers were positive about using ICT in inclusion classes, stressing as a major benefit of using them that they focused on diversity of students. In addition, teachers indicated that ICTs can be adapted to the diversity of students in the classroom, stimulating students' interest in learning and acquiring knowledge, while enhancing both individual and collaborative learning among students. Finally, the findings of the research on teachers who had access to ICT tools were significant, as they were found to be more positive in their classroom use.

A report by Becta [23], which analyzed the available literature on the use of ICTs to support special education and inclusion classes, highlights the major benefits that ICT utilization in special education classes can offer. Initially, ICTs enhance students' autonomy during the learning process, while providing them with modern tools to showcase their abilities and skills, which perhaps could not be achieved using traditional methods and tools. In addition, these modern tools offer new communication opportunities to students who are experiencing difficulties in this area, facilitating them. Particularly important is the opportunity for students to work at their own pace. The use of computers in the classroom, familiarizes students with the use of ICTs and motivates them to make further use of them at home, for educational or recreational purposes. However, utilizing ICT in special education or inclusion class, however, not only benefits students but also teachers. In particular, teachers can find useful material for their students online and in a format that is in line with their needs, which is even easier to modify to suit their needs, such as the use of larger fonts or images to help students with visual impairments. ICTs also allow teachers to interact more effectively with their peers and to communicate, be informed, discuss and exchange ideas about the curriculum and the teaching methods they follow, enriching and expanding their knowledge. ICTs also help teachers to develop their skills and enrich their knowledge by learning to use the tools they offer to maximize learning outcomes.

However, in spite of the benefits that ICT can offer in special education, it 
seems that their use has not yet expanded to the desired extent, and the difficulties encountered in applying ICT to the general public continue to exist in the field of special education [20]. Inadequate knowledge and training of teachers on the use of ICTs and the variety of tools they offer, the lack of knowledge about the pedagogical role of ICT, the lack of infrastructure and adequate funding to equip classrooms with modern computers and software, the "fear" technology and the preference for traditional methods are perhaps the main reasons for the use of ICT in the classroom, especially in the field of special education [24].

From the foregoing, it is understood that the use of ICTs in the field of education, whether it be for general or special education, is an interesting subject to explore, which may offer a variety of different interpretations for their use or not to the teachers. Although there is now a notable change in the educational model followed in Greek schools, a shift from teacher-centered to student-centered, with the student taking an active role in acquiring knowledge and the teacher no longer being considered authentic and knowledge holder, it is noteworthy that, despite advances in technology, ICTs seem to be less exploited than expected, especially in special education and co-educational classes, despite the fact that they can offer new learning opportunities of students facilitation tools with disabilities and assist their integration [25].

\subsection{Use of Information and Communication Technologies in Students with Autism Spectrum Disorder}

As mentioned earlier, ICTs provide tools to facilitate the communication of students with disabilities in this area, while allowing them to cultivate their skills and experience the learning experience with all their senses. It would, therefore, be expected that ICT could be used to a greater extent in special education classes, as they could potentially be particularly effective for students with autism spectrum disorders. According to the latest version of the Diagnostic and Statistical Manual of Mental Disorders-V (DSM-V for short), autism falls into the category now known as Autistic Spectrum Disorders (ASD) [1]. Until the fourth edition of the handbook, it is noted that autism falls into the category of so-called Diffuse Developmental Disorders (DDD), a name given to them due to the clinical picture of the symptoms that were simultaneously disseminated to multiple developmental [26].

Autism is often referred to as a "childhood disorder", as the first symptoms of the disorder appear in early childhood. In most cases, autism is diagnosed in the first 5 or 6 years of a child's life, although it is now possible to diagnose it even at an early age. A key prerequisite for evaluating a child and diagnosing him with autism is that the symptoms have occurred no later than the first three years of the child's life [26]. Autism, as a spectrum disorder, can vary with the severity of the symptoms and the number of symptoms a child presents, as well as the degree of mental retardation, if any, he or she has, as there are few cases of autistic children, with normal or even extremely high levels of intelligence. DSM-V and ICD are used to diagnose autism. The DSM-V includes two categories of diag- 
nostic criteria [26].

Problems in social communication.

Stereotypical, repetitive behaviors, activities and interests.

Symptoms that a child may experience vary and may be related to different developmental areas. However, some of the most prominent features of the disorder are the lack of visual contact, delayed speech development and incomplete vocabulary, difficulty in understanding other people's emotions, limited use of meaning, facial expressions, gestures and body language in general, non-imitation of other people, echolalia, lack of empathy, stereotypical and repetitive behaviors, aggression, anger bursts, inappropriate social situations, loneliness, the inability to create social relations, repetition of sounds, muscle atrophy, the rhythmic rocking of the body and deficits in the development of coarse and fine motor [5] [27].

From the above, it is understood that children with autism are faced with a multitude of difficulties from their earliest years, which place obstacles in their lives and deprive them of experiences that every human being has the right to enjoy. Indeed, in view of the above-mentioned symptoms, it is clear that one of the critical areas in which autistic children have deficits is the emotional one, where there is a lack of empathy, emotional attachment, lack of communication, relationships and intense loneliness. However, ICTs can provide children with autism with tools that will enable them to communicate, explore their emotional world, cultivate it and acquire valuable tools that are extremely useful for their integration into school and society.

Charitaki's research [28], which sought to investigate the effects of ICT on the emotional education of children with autism, is of particular interest. Initially, it is worth noting that the five participants in the study had great difficulty in understanding the expressions of emotions in their daily lives, and their mental age ranged from five to seven years. The intervention, which lasted ten weeks, with two sessions per week of thirty minutes, utilized the game's "MoodMaker" software, which teaches children emotions through different environments and specifically which emotions (e.g. negative or negative) correspond to specific situations, utilizing image and sound. The findings of the study showed that children made significant progress in understanding their emotions and could more easily describe how they felt, as their parents reported. Also, the software used has turned out to be an extremely useful and effective tool, with understandable instructions and high ease of use, even without the presence of the teacher.

Equally interesting is the research by Chen et al. [29], which used augmented reality technology to train participants, three adolescents with autism, in understanding the emotions and expressions of the individuals accompanying them. All three participants, despite having aesthetic abilities within the normal range and with no cognitive developmental deficits, had difficulty communicating, socializing, and understanding emotions, leading them to use incorrect facial expressions to respond to other people's emotions. For the purposes of the research, photographs of the participants were used, from which $3 \mathrm{D}$ models with 
six different expressions were created using $3 \mathrm{~d}$ s Max software and then using the Unity engine to take on the augmented reality. Participants then, wearing special masks depicting different emotions, could see themselves on a computer screen with a three-dimensional model of this expression on their virtual faces, and then try to emulate and understand the context in which can be used. Although participants at the beginning had difficulties in understanding the emotions, with the continuous interventions, they made significant progress, with the rate of feeling understanding increased from $20 \%$ to $96.43 \%$, which was maintained even after the intervention was repeated.

In subsequent investigation of Didehbani et al. [30], a virtual reality program to train people with autism in social knowledge was utilized. Thirty children aged seven to sixteen with intelligence at or above normal levels participated in the study. For the purposes of the research, the virtual world of "Second Life" was utilized to provide participants with different environments for exploration, such as a fast food shop, a school room, a park, a playground, etc. The image that represented each participant in the virtual environment had been adapted to the external features of its appearance to resemble it. Through different social situations presented in the virtual reality world, participants learned rules of social behavior, how to recognize others' emotions, and how to adapt their behavior and expressions to them. To provide assistance and guidance, clinical psychologists were involved, who took on the role of another character in the virtual world, initiated discussions, advised participants to better understand the scenario they were in and the way they should express themselves by giving feedback. Research findings have shown that the virtual environment is a safe place for children with autism, where they can experience different social circumstances without fear and shame and experiment. In addition, it attracts the interest of children and is fun. Finally, this intervention was successful, as there was an improvement in the recognition of emotions, in the executive functioning of proportionate reasoning and in social performance.

Cheng et al.'s research [31], utilized a virtual collaborative learning environment for the education of children in the autism spectrum of empathy. The study involved three children, boys aged eight to ten, who were on the autism spectrum and who had significant empathy deficits. For the purposes of the research, a 3D virtual reality environment, similar to the "Second Life" of the previous research, has been exploited, which emphasizes scenarios that cultivate children's empathy, with the exception that the children acted this time only in an environment, that of a restaurant. The intervention, along with the repetitive sessions, lasted for almost five months and each session lasted forty minutes. Children were asked questions and answers about different social scenarios and then had to choose on the basis of whether they disagreed or agreed on how they would react to that scenario. The findings of the study showed that children were increasingly interested in the program and found it fun, prompting them to become actively involved in the learning process. In addition, research has 
shown that the program has significantly enhanced children's empathy, and over time.

In Ip et al.'s research [32], a virtual reality approach to improve the emotional and social adaptive abilities of children with autism was utilized. The study involved 94 children in the autism spectrum, from six to twelve years old. For the purposes of the research, six different training scenarios were utilized in a virtual environment, one focusing on emotion management and relaxation techniques, four simulating social situations and one enhancing stabilization and generalization. After completion of the intervention, which lasted 14 weeks, the children showed a significant improvement in the expression and management of emotions and social interaction with other individuals.

Similar findings to the surveys presented so far have been brought to light by Lorenzo et al.'s research as well [33]. For the purposes of the research, a virtual reality system was created to provide users with an immersive experience. The study involved 40 students from the age of seven to twelve who are on the autism spectrum and have difficulties in the social and emotional field. By providing different social scenarios to the children, the researchers recorded their facial expressions, which were then visualized in virtual environments to record whether or not they responded to the social situation. Research has shown that virtual reality environments provide children with greater interaction, develop their imagination, and contribute to improved emotional understanding and, by extension, children's social interactions in the real school environment. It can be seen from the above that ICT has many benefits for students with autism, as they can help with their emotional education and thus enhance their socialization and facilitate their integration into school and classroom.

\section{Research Methodology}

\subsection{Research Method}

The research conducted has some characteristics, as it is educational research. Through the exploitation of educational research, the researcher aims to bring four different kinds of knowledge to the field of education. In the description, the researcher sets out to gather data that accurately describes some phenomena observed in the field of education, utilizing appropriate tools that provide accurate measurements. As far improvement is concerned, the researcher focuses on exploring practices that can be utilized to overall improve and assist the educational process, students' and teachers' work. In prediction, the researcher collects data that will help him predict a phenomenon related to the field of education, such as students' future performance. Finally, in the justification, the researcher is asked to consider a phenomenon from many different perspectives, in order to be able to describe it in detail, identify the causes associated with its occurrence, predict its future development and control factors influencing it, developing a theory to explain and understand the complexity of the phenomenon [34].

The purpose of this research is to bring new knowledge to the forefront, de- 
scribing and analyzing the phenomenon in depth, identifying the causes associated with the occurrence of the phenomenon, identifying possible solutions to the phenomenon and future improvement of the situation existed in the area of special education and training.

The qualitative method was chosen according to the purpose and type of the research, the individual objectives and the research questions. So the method used is the qualitative research approach.

\subsection{Types of Interviews}

Depending on the degree of construction or standardization of the interview by the researchers, we can distinguish semi-structured and unstructured qualitative interview. In these types of interviews, researchers strive to produce the richest research material possible by giving participants the opportunity to talk freely and in depth about their perceptions, thoughts or experiences (Robson, 2007). In-depth semi-structured interviewing consists of a set of somewhat pre-defined questions and is often used by young qualitative researchers to have a guide to the topics they consider important to cover in the interview. It should be noted here that this type of interview is flexible: 1) modifying the content of the questions according to the respondent; 2) to delve into some issues with participants deemed appropriate; 3) with the order in which the questions are asked; and 4) adding or removing questions or topics for discussion.

The unstructured interview is open and does not include predetermined questions, but broad themes on which the research participants are invited to speak or place freely on their own terms. In particular, the researcher usually forms a list of 7 or 8 topics that he/she considers important and on which the interaction between the interviewer and the participants in the research process is formed. A particularly important advantage of this approach is the emergence of new themes through the participants' own words, which were not predetermined by the researchers (Mason, 2009; Robson, 2007).

A fully structured interview is hardly used in qualitative research, as it is based on strictly predetermined questions about the content, wording and order in which the questions are asked and does not allow for in-depth data collection or the emergence of new topics. The use of mainly open-ended questions is the only significant difference from a sample questionnaire using interviews (Robson, 2007).

\subsection{Designing and Conducting Qualitative Interviews}

In general, planning and conducting qualitative interviews is a complex and demanding task that requires systematic preparation by researchers. A particularly important dimension in a research that adopts qualitative interviewing is the design and formulation of the questions before conducting them. However, the interviewer needs to be able to make decisions on the spot during the interview e.g. the order, wording, style, extent, or addition of questions, always having in 
mind the research questions but also the specific circumstances and interaction with the participants.

Therefore, for the needs of the research, the qualitative research method was chosen, as it is fully consistent with the purpose, aims and research questions of the research, since the purpose is not to record the specific educators and psychologists who use ICT (or not) for emotional education of children with autism, but a deeper understanding of their attitude, their views on them in general and in particular their effectiveness, and the causes that have led to their respective positive or negative or attitudes that maintain towards them.

\subsection{Sampling}

The choice of the sample was based on the sampling method of the snowball. Snowball sampling or Chain-referral-sampling of a hidden population begins with a convenience sample of initial subject, because if a random sample could be drawn, the population would not restrict as hidden [35]. As with random sampling, the snowballing method is not as uncontrolled as its name implied. The researcher is deeply involved in developing and managing the origination and progress of the sample, and seeks to ensure at all times that the chain of referrals remains within limitations that are relevant to the study. One of the dangers with snowball sampling is that respondents often suggest others who share similar characteristics, or the same outlook, and it is also compulsory on the researcher to ensure that the initial set of respondents is sufficiently varied so that the sample is not skewed excessively in any one particular direction.

Initially, five individuals from the broader social context of the researcher were approached, all of whom were readily available and had the desired characteristics to participate in the research. Subsequently, these participants provided access to eight more individuals with the desired characteristics, who in turn contacted the researcher with seven other individuals who met the criteria for participation in the research, thereby completing the desired number of the participants.

The final sample of participants in the study is made up of specialist educators and psychologists. The total number of participants was 20, 10 of whom were special educators and the remaining 10 were psychologists.

\subsection{Data Collection Tool}

Both the research sample and the research tool used in conducting it are extremely critical to its success and validity, and their proper choice is crucial to its outcome. In the present study, a tool frequently used in qualitative surveys was used and this is a semi-structured interview.

The semi-structured interview is a form that contains a set of predefined questions that the researcher has selected and that are consistent with the research needs. However, the semi-structured interview offers the researcher more flexibility than the strictly structured interview, allowing him to put in different 
words and order the questions he has prepared, omitting some if necessary and even asking additional questions if a new aspect of the issue emerges during the interview that is considered important to be further explored and which was not foreseen in the planning of the questions. The characteristics of the semi-structured interview, and the advantages it offers in terms of greater freedom, were crucial to its final choice.

Regarding the questions included in the semi-structured interview, they were designed taking into account the purpose, objectives, research questions of the research and the characteristics of the participants, and after a thorough study of the relevant topic, literature and more specifically, came from the scientific studies of [28] [36] [37] [38].

\subsection{Research Procedure}

The research process involves all stages of the research, both before and after it is completed. During the preliminary stages, the researcher studied the existing literature on the subject, designed the interview form, and drafted the Research Ethics and Ethics Form, after which she received the College's approval to proceed with the formal research.

The process of identifying participants and conducting interviews lasted from May 6, 2019 to June 3, 2019 and took place in Athens. As mentioned earlier, the first five participants in the research came from the broader social context of the researcher, and subsequently provided access to more participants in the avalanche sampling method. The interviews were conducted at the participants' home without the presence of a third party, in order to ensure the objectivity of the respondents' answers and, consequently, the reliability of the survey results. The mean duration of the interviews ranged from 25 to 35 minutes and the researcher's mobile phone was used to record them.

Each videotaped interview was then transcribed, typed in Microsoft Word and, along with written notes from each interview, transferred to a personal computer and organized into separate folders with identifiers. After all interviews with the participants were completed, the researcher proceeded with their analysis.

\section{Data Analysis}

The thematic analysis was used to process the respondents' responses. According to this method of analyzing qualitative data, the participants' raw responses are organized and analyzed in a detailed and easily understood manner [39].

Initially, the researcher studied each interview several times in order to understand the respondents' answers, their way of expressing themselves and to identify common or conflicting data among them. Then the common points of their answers were identified and coded using specific keywords and code numbers. They then identified the common points of their answers and coded them using specific keywords and code numbers. 
At the completion of this stage, the common but also conflicting elements identified in the participants' responses were presented, analyzed and contrasted with the data and information extracted through the bibliographic review. In this way, the phenomenon under investigation becomes deeper understood, answers to the research questions that have been asked and confirms whether or not the findings are compared to the findings of previous research [40].

Thematic analysis is a method widely used in the qualitative research method and especially for the analysis of interviews. It is a well-pointed and detailed process that allows the researcher to understand the interviewees' answers more thoroughly through their in-depth study and discussion. In addition, it allows the raw data to be organized in a correct, logical and understandable way, facilitating the identification of similarities and differences between respondents' answers, which serves to analyze them and then link them to previous international research data, thus providing a more comprehensive understanding of the issue under investigation.

\section{Ethical Issues}

Ethics is a very important concept in the field of research. Adherence to ethical rules at every stage of the research process and appropriate measures are necessary to ensure the proper conduct of the research, to protect participants from exposure to risks, to safeguard their rights, and ensuring the validity and reliability of the research findings as well.

Starting from the ethics of the research, it focuses on the participants and their rights during the research process. Participants therefore have the right to know the real purpose of the research and must therefore be informed in writing and orally about their subject matter, in order to give their consent consciously and responsibly, which must always be in line with the spirit of democracy and the subject's right to free self-determination. For this reason, the researcher must inform participants that they have the right to refuse to participate in the research, even if they have given their initial consent, at any time, without any penalties and the requirement to justify their withdrawal. On the other hand, participants need to know that their consent and participation in the research is accompanied by obligations and responsibilities to which they have clearly consented.

In the context of the above, the ethics of the research was ensured and the participants became aware of their rights and obligations. The Participant Information Form and the Participant Consent Form given to psychologists and special educators respectively, clearly and in detail describe the purpose of the research, its context, the methodology to be followed, their rights and obligations regarding the protection of their personal data and the refusal to participate in the investigation. In addition, the researcher provided details of the educational institution and the program she is attending and provided her contact information so that the participants would be able to contact her at any time, 
and their explicit, signed consent was obtained to participate in the research.

As far as research ethics are concerned, this is ensured through the researcher's good practices in collecting, storing and destroying the personal data she has collected in the course of her research by the participants. The researcher is therefore obliged to inform participants of the manner and context of the use of their personal data, as well as how they will be used after the end of the research and if they have ceased to serve their processing and storage purposes [35].

In particular, they were informed of their anonymity and the confidentiality of their sensitive information, which were disclosed only to the researcher and solely for the purpose of the research. The researcher also took additional steps to protect participants' data. All material (notes, transcripts) was transferred electronically to her personal computer, which is protected by a strong security code, also in password protected folders. Upon completion of the analysis of the research data, the researcher destroyed all printed and electronic material in her possession.

\section{Issues of Validity and Reliability}

Each step described up to this point is absolutely critical to ensuring the high reliability and validity of the procedures followed and, by extension, the results of this research. Any omission or irregularity, however, could impede the smooth conduct of the research and endanger both the participants and the researcher as well as the quality and scientific value of the results obtained through it [41].

Understanding, therefore, the great and important responsibility that accompanies any research effort and the researcher's debt towards the participants and the scientific community, the researcher has taken the necessary steps to assure, to the extent possible, its high validity and reliability of the research.

Initially, each stage of research design, selection of the appropriate tool and formulation of questions was based on prior scientific research and publications of international and Greek literature. Every step of the research process followed by targeting, formulating research questions, sample selection and interview questions is based on international, appropriate research practices.

In addition, the research participants received written and oral information on the subject of the research, as well as instructions on the procedure to follow and had the opportunity to express their questions and receive immediate clear answers. Finally, the absence of third parties that could in any way influence the participants in conducting the interviews further enhanced the validity and objectivity of their responses.

\section{Results}

The teaching staff in a school unit, and in particular in special education, are considered very important as they are the ones who support and boost children with special educational needs so that both pupils and their parents are always satisfied with the result. Special educators (in this case special educators and 
psychologists) are a link in order for the proper functioning of a school community and a strong image of the special education school unit to take place. This achievement, however, is extremely difficult and to succeed it requires the cooperation of all executives, such as the headmaster, the supervisor, the parents, the social workers, the psychologists, etc. After all, a school unit, without the contribution of all staff and external partners, cannot be fully effective. Harmonious relationships between all involved in a school-specific unit are the key to a successful and productive term for all students in a special class.

In most countries there is no particular national policy for the integration of ICT in Special Education. The general policy of integrating ICT in education promotes the provision of equal opportunities for education around, from and through ICT. In some countries, national education policy provides for special education students the same rights as all other students, and this includes access to appropriate ICTs (Zoniou -Sideri, 2004) [42].

The rapid development of Information and Communication Technologies (ICT) affects all areas of human activity and Education is no exception. The trends that are being shaped by the Modern School pedagogical approaches are the application of ICT with emphasis on collaborative learning, removing space and time constraints on learning, developing critical thinking, changing the role of the teacher from instructor to mentor and leader and the view that class and school are learning tools that are flexible and open to society [43].

The design of ICT applications and use in education is based on pedagogical theories and learning theories (Behavioral, Building and Socio-cultural Approaches), which provide the appropriate theoretical framework for formulating key specifications governing computational support for teaching.

Exploratory and discovery learning succeeds in a sterile teacher-centered knowledge transfer, and with the use of ICT, a climate of fruitful and constructive collaboration between teachers, students and society is formed. It goes without saying that the teacher needs to provide pedagogical support, training and technical tools to carry out his/her new role through an integrated training methodology [42].

As Raptis and Rapti [20] report, the computer can be used not only as a teaching tool and source of information but also as a powerful cognitive development tool, thanks to its many properties, which provide excellent capabilities for creating a fertile and advanced learning environment, which, with the appropriate intervention of the teacher, favors the functioning and development of students at higher levels of learning and communication, as well as the implementation of many modern teaching principles, which are not easy to adopt in the traditional classroom [42].

In the international literature there are numerous references to the advantages of using the computer in educational practice. According to Poole, in 1997, there are five main reasons that dictate the use of ICT in the educational process as follows: 
learning support,

teaching aids,

helping to socialize the child,

assisting the social integration of children with disabilities (e.g. learning difficulties or mobility problems),

assisting teachers' creativity and effectiveness [42].

Finally, it is mentioned that the computer can be used as a Mind tool. The purpose of these mental or cognitive tools is to foster constructive learning, in which the learner builds on his/her knowledge and does not simply repeat the knowledge he/she received from the teacher. This particular function of the computer can contribute to the development of creative learning, provided that appropriate software training environments are always used.

To introduce the computer to the classroom and integrate it into the learning process requires the change of the traditional classroom, as well as the role of both the teacher and the student. Using the computer as a learning tool enables the learner to become an active part of the educational process, to work at their own pace and according to their own abilities. On the other hand, the teacher becomes a student organizer and mentor by eliminating the school-centered perceptions of the school. The use of ICT favors equal opportunities for all children, regardless of race, gender, socio-economic background [42].

\section{Conclusions}

The results of the research lead to some findings. It is understood that specialized staff (in a great percent) do not have sufficient knowledge of the field of special education and in particular of the use of New Technologies used for Emotional Education of children with ASD. In addition, it is crucial to emphasize more and more incentives for teachers to be trained in New Technologies. By continuously organizing seminars and reducing tuition or fees, their knowledge will be enhanced, especially in the field of New Technologies for children with ASD. It is worth noting that in Special Education, the use of Computers, according to the literature review, can produce positive results in a timely manner.

One particular element that emerged through research is the fact that children with autism do not make use of the New Technologies easily. This finding was confirmed by the subjects' responses, and there is a possible association between non-use due to depreciation by the teachers themselves.

Finally, the financial problems our country faces are a hindrance in the field of New Technologies. For example, I quote the response of the special educator as stated in the annex on this subject: "Schools and centers dealing with children with autism may not have the necessary materials and equipment due to financial problems which is one of the main problems".

\section{Recommendations}

Based on the above, some suggestions are presented. Future research efforts with 
a larger sample, as well as other specialty teaching staff specialties, as well as students with ASD, are considered necessary.

Another interesting future proposal could be to explore appropriate different methods of intervention using specific software for children with autism. The results of these studies could further illuminate the field of emotional education and self-regulation [41] in children with autism. At the same time, the most effective interventions to empower children with ADHD could be highlighted, given all the special software available in schools.

In addition, future research could focus on comparing specific software used for children with autism. The findings would be particularly useful in highlighting the importance of all software in order to take into account both the weaknesses and the strengths of all software. It is very important to research interaction with people with disabilities and how we can promote them [44].

\section{Limitations}

The research design included mixed methodological approach, which is able to triangulate. Though, there were various limitations. One limitation is related to the limited size of the sample which consists of 20 participants. Additional research is needed to be conducted with a larger sample of participants. Given the insufficient research data in the field of ASD in Greece, the conclusions drawn from this study are considered important and are expected to enrich the scientific research and trigger new studies. The research data can be considered for a future enrichment through further pilot research with the exploitation of information and through quality research methods. Valuable material and essential feedback can be derived from interviews with special educators, thus achieving a thorough collection of qualitative data. An additional future perspective of research may include the assessment of the intervention programme through the use of ICT, more specifically, a study on the effect of the use of iPad to intervene in children with ASD in creating a functional writing system and eliminating spelling errors [45].

\section{Acknowledgements}

This study would not have been possible without the contribution of numerous people. We would like to thank the educational staff who took part in the research.

\section{Conflicts of Interest}

The author declares no conflicts of interest regarding the publication of this paper.

\section{References}

[1] American Psychiatric Association (2013) Diagnostic and Statistical Manual of Mental Disorders. 5th Edition, APA, Washington DC. 
https://doi.org/10.1176/appi.books.9780890425596

[2] Newschaffer, C.J., Croen, L.A., Daniels, J., Giarelli, E., Grether, J.K, Levy, S.E., Mandell, D.S., Miller, L.A., Pinto-Martin, J., Reaven, J., Reynolds, A.M., Rice, C.E., Schendel, D. and Windham, G.C. (2007) The Epidemiology of Autism Spectrum Disorders. Annual Review of Public Health, 28, 235-258. https://doi.org/10.1146/annurev.publhealth.28.021406.144007

[3] Elsabbagh, M., Divan, G., Koh, Y.J., Kim, Y.S., Kauchali, S., Marcín, C., Montiel-Nava, C., Patel, V., Paula, C.S., Wang, C., Yasamy, M.T. and Fombonne, E. (2012) Global Prevalence of Autism and Other Pervasive Developmental Disorders. Autism Research, 5, 160-179. https://doi.org/10.1002/aur.239

[4] Baird, G., Charman, T., Cox, A., Baron-Cohen, S., Swettenham, J., Wheelwright, S. and Drew, A. (2001) Current Topic: Screening and Surveillance for Autism and Pervasive Developmental Disorders. Archives of Disease in Childhood, 84, 468-475. https://doi.org/10.1136/adc.84.6.468

[5] Tsafoutis, B. and Tsolakis, G. (2010) The Assessment of Autism. Unpublished Thesis, Technological Educational Institute of Epirus, Ioannina.

http://apothetirio.teiep.gr/xmlui/bitstream/handle/123456789/443/lgt_2010009.pdf? sequence $=1$

[6] Grynszpan, O., Weiss, P.L., Perez-Diaz, F. and Gal, E. (2014) Innovative Technology-Based Interventions for Autism Spectrum Disorders: A Meta-Analysis. Autism, 18, 346-361. https://doi.org/10.1177/1362361313476767

[7] Hayes, G.R., Hirano, S., Marcu, G., Monibi, M., Nguyen, D.H. and Yeganyan, M. (2010) Interactive Visual Supports for Children with Autism. Personal and Ubiquitous Computing, 14, 663-680. https://doi.org/10.1007/s00779-010-0294-8

[8] Ramdoss, S., Lang, R., Fragale, C., Britt, C., O’Reilly, M., Sigafoos, J. and Lancioni, G.E. (2012) Use of Computer-Based Interventions to Promote Daily Living Skills in Individuals with Intellectual Disabilities: A Systematic Review. Journal of Developmental and Physical Disabilities, 24, 197-215.

https://doi.org/10.1007/s10882-011-9259-8

[9] Shane, H.C. and Albert, P.D. (2008) Electronic Screen Media for Persons with Autism Spectrum Disorders: Results of a Survey. Journal of Autism and Developmental Disorders, 38, 1499-1508. https://doi.org/10.1007/s10803-007-0527-5

[10] Franchini, M., Duku, E., Armstrong, V., Brian, J., Bryson, S.E., Garon, N. and Smith, I.M. (2018) Variability in Verbal and Nonverbal Communication in Infants at Risk for Autism Spectrum Disorder: Predictors and Outcomes. Journal of Autism and Developmental Disorders, 48, 3417-3431.

https://doi.org/10.1007/s10803-018-3607-9

[11] Lee Heward, W. (2011) Childrens with Special Needs, an Introduction to the Special Education. Topos, Athens, Greek.

[12] Asaro-Saddler, K., Knox, H.M., Meredith, H. and Akhmedjanova, D. (2015) Using Technology to Support Students with Autism Spectrum Disorders in the Writing Process: A Pilot Study. Insights into Learning Disabilities, 12, 103-119.

[13] Taylachidis, S. (2014) ICT Applications in Special Education. Teachers, 109-110, 227-240.

[14] Leong, L. and Jarmoszko, A.T. (2010) Analyzing Capabilities And Enterprise Strategy: A Value Proposition Framework. International Journal of Management \& Information Systems, 14, 54-60. https://doi.org/10.19030/ijmis.v14i1.823

[15] Karakiza, T. (2007) Information and Communication Technologies in the Class- 
room. http://users.sch.gr/tsakarak/?page_id=130

[16] Gorghiua, L.M., Gorghiub, G., Bîzoib, M. and Suducb, A.M. (2011) The Electronic Book: A Modern Instrument Used in Teachers' Training Process. Procedia Computer Science, 3, 563-567. https://doi.org/10.1016/j.procs.2010.12.093

[17] Becker, H.J. (2001) How Are Teachers Using Computers in Instruction? Paper Presented at the Annual Meeting of the American Educational Researchers Association, Seattle, WA.

[18] Russell, M., Bebell, D., O’Dwyer, L. and O’Connor, K. (2003) Examining Teacher Technology Use: Implications for Preservice and Inservice Teacher Preparation. Journal of teacher Education, 54, 297-310. https://doi.org/10.1177/0022487103255985

[19] Damamogia, T. (2009) Exploiting ICTs Education and Inclusion of Children with Disabilities in the School and Wider Social Environment. Proceedings of the 5 th Panhellenic ICT Teachers Conference, Syros.

[20] Raptis, A. and Raptis, A. (2006) Learning and Teaching in the Information Age, Volume I. Self-Publishing, Athens.

[21] Crawford, K. (1996) Vygotski an Approaches in Human Development in the Information Era. Educational Studies in Mathematics, 31, 43-62. https://doi.org/10.1007/BF00143926

[22] Fernández Batanero, J.M. and Colmenero Ruíz, M.J. (2016) ICT and Inclusive Education: Attitude of the Teachers in Secondary Education. Journal of Technology and Science Education, 6, 19-25. https://doi.org/10.3926/jotse.208

[23] Becta (2003) What the Research Says about Video Conferencing in Teaching and Learning, from the Becta's What the Research Says Series.

http://www.becta.org.uk/page_documents/research/

[24] Teo, T. (2009) Modelling Technology Acceptance in Education: A Study of Pre-Service Teachers. Computers \& Education, 52, 302-312. https://doi.org/10.1016/j.compedu.2008.08.006

[25] Roberts, L. (2011) Primary Schools and ICT-Learning from Pupil Perspectives. London Review of Education, 9, 351-352. https://doi.org/10.1080/14748460.2011.616330

[26] Magnisalis, S. and Saya S. (2014) Diagnostic Criteria for Autism Spectrum Disorders. http://www.autismhellas.gr

[27] Varvoglis, L. (2006) The Diagnosis of Autism: A Practical Guide. Kastaniotis, Athens.

[28] Charitaki, G. (2015) The Effect of ICT on Emotional Education and Development of Young Children with Autism Spectrum Disorder. Procedia Computer Science, 65, 285-293. https://doi.org/10.1016/j.procs.2015.09.081

[29] Chen, C.H., Lee, I.J. and Lin, L.Y. (2015) Augmented Reality-Based Self-Facial Modeling to Promote the Emotional Expression and Social Skills of Adolescents with Autism Spectrum Disorders. Research in Developmental Disabilities, 36, 396-403. https://doi.org/10.1016/j.ridd.2014.10.015

[30] Didehbani, N., Allen, T., Kandalaft, M., Krawczyk, D. and Chapman, S. (2016) Virtual Reality Social Cognition Training for Children with High Functioning Autism. Computers in Human Behavior, 62, 703-711.

https://doi.org/10.1016/j.chb.2016.04.033

[31] Cheng, Y., Chiang, H.C., Ye, J. and Cheng, L.H. (2010)Enhancing Empathy Instruction Using a Collaborative Virtual Learning Environment for Children with Autistic 
Spectrum Conditions. Computers \& Education, 55, 1449-1458. https://doi.org/10.1016/j.compedu.2010.06.008

[32] Ip, H.H., Wong, S.W., Chan, D.F., Byrne, J., Li, C., Yuan, V.S., Lau K.S.Y. and Wong, J.Y.W. (2018) Enhance Emotional and Social Adaptation Skills for Children with Autism Spectrum Disorder: A Virtual Reality Enabled Approach. Computers \& Education, 117, 1-15. https://doi.org/10.1016/j.compedu.2017.09.010

[33] Lorenzo, G., Lledó, A., Pomares, J. and Roig, R. (2016) Design and Application of an Immersive Virtual Reality System to Enhance Emotional Skills for Children with Autism Spectrum Disorders. Computers \& Education, 98, 192-205. https://doi.org/10.1016/j.compedu.2016.03.018

[34] Papanastasiou, K. and Papanastasiou, E. (2005) Educational Research Methodology. Cyprus Institute of Education, Nicosia.

[35] Heckathorn, D.D. (2015) Snowball versus Respondent-Driven Sampling. Sociological Methodology, 41, 352-366. https://doi.org/10.1111/j.1467-9531.2011.01244.x

[36] Williams, P., Jamali, H.R. and Nicholas, D. (2006) Using ICT with People with Special Education Needs: What the Literature Tells Us. Aslib Proceedings, 58, 330-345. https://doi.org/10.1108/00012530610687704

[37] Yildirim, S. (2000) Effects of an Educational Computing Course on Preservice and in-Service Teachers: A Discussion and Analysis of Attitudes and Use. Journal of Research on Computing in Education, 32, 479-495. https://doi.org/10.1080/08886504.2000.10782293

[38] Braun, V. and Clarke, V. (2006) Using Thematic Analysis in Psychology. Qualitative Research in Psychology, 3, 77-101. https://doi.org/10.1191/1478088706qp063oa

[39] Sarantakos, S. (2012) Social Research. Palgrave Macmillan, New York.

[40] Creswell, J.W. and Maietta, R.C. (2002) Qualitative Research. In: Miller, D.C. and Salkind, N.J., Eds., Handbook of Social Research, Sage, Thousand Oaks, CA, 143-184.

[41] Charitaki, G., Soulis, S.G. and Tyropoli, R. (2019) Academic Self-Regulation in Autism Spectrum Disorder: A Principal Components Analysis. International Journal of Disability, Development and Education, 2019, 1-20. https://doi.org/10.1080/1034912X.2019.1640353

[42] Zoniou-Sideris, A. (2004) Teacher Training. Hellenic Letters, Athens.

[43] Matsagouras, H. (2003) The Classroom: Space, Group, Discipline, Method. Grigoris, Athens.

[44] Bania, T.A., Antoniou, A.S., Theodoritsi, M., Theodoritsi, I., Charitaki, G. and Billis, E. (2019) The Interaction with Disabled Persons Scale: Translation and Cross-Cultural Validation into Greek. Disability and Rehabilitation, 2019, 1-8. https://doi.org/10.1080/09638288.2019.1643420

[45] Charitaki, G., Soulis, S.-G., Tzivinikou, S. and Peklari, E. (2018) Morphological Skills: A Key Para-Meter in Dealing with Written Expression and Spelling in Specific Learning Disabilities. Creative Education, 9, 879-900.

https://doi.org/10.4236/ce.2018.96065 